\title{
A Union Operation of Non-Dominated K-Coterie in Distributed System
}

\author{
Operasi Union K-Koteri Tak Terdominasi pada Sistem Terdistribusi \\ Nurhidayah $^{1)}$, Armin Lawi ${ }^{2)}$, Amir Kamal Amir ${ }^{3)}$
}

\begin{abstract}
Coterie is a set of quorums which has non-empty intersections and are not part of other quorum. The natural development of the coterie system is k-coterie. The k-coterie consists of 2 types, that are non-dominated k-coterie and dominated $\mathrm{k}$-coterie. The non-dominated $\mathrm{k}$-coterie is more resilient to failure than the dominated $\mathrm{k}$-coterie. Combining two non-dominated k-coterie by applying union operation can result the dominated k-coterie. This study aims to define a combination of the non-dominated k-coterie with non-dominated k-coterie using the expanded union operation. The merger of non-dominated $\mathrm{k}$-coterie with the non-dominated $\mathrm{k}$-coterie produces a nondominated k-coterie.
\end{abstract}

Keywords : Quorums, non-dominated k-coterie, expanded union operation

\begin{abstract}
Abstrak
Koteri merupakan himpunan dari beberapa korum yang saling beririsan satu sama lain dan bukan merupakan bagian dari korum yang lainnya. Pengembangan alami dari sistem koteri adalah $k$-koteri. $K$-koteri terdiri atas 2 jenis yaitu, $\mathrm{k}$-koteri tak-terdominasi dan $k$-koteri terdominasi. Koteri tak-terdominasi lebih tangguh terhadap kegagalan dibandingkan koteri terdominasi. Menggabungkan dua $k$-koteri tak-terdominasi menggunakan operasi union biasa menghasilkan $k$-koteri terdominasi. Pada penelitian ini, penulis membangun definisi penggabungan $k$-koteri takterdominasi dengan $k$-koteri tak terdominasi menggunakan operasi union yang diperluas. Penggabungan $k$-koteri tak-terdominasi dengan $k$-koteri tak-terdominasi menghasilkan $k$-koteri tak-terdominasi.
\end{abstract}

Kata kunci: Korum, k-koteri tak-terdominasi, operasi union diperluas

\section{PENDAHULUAN}

Lawi dkk [1] menjelaskan bahwa dalam sistem terdistribusi, sumber daya hanya dapat diakses oleh paling banyak 1 proses dalam suatu waktu. Apabila terdapat beberapa proses yang bersaing secara simultan untuk mengakses sumber daya tersebut maka akan minumbulkan konflik yang di sebut masalah mutual eksklusion.

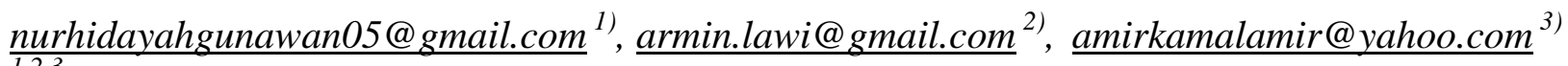
${ }^{1,2,3}$ Jurusan Matematika Terapan, Program Pascasarjana, Universitas Hasanuddin 


\section{Nurhidayah, Armin Lawi, Amir Kamal Amir}

Algoritma sinkronisasi dalam sistem terdistribusi secara sederhana dapat dipandang sebagai sebuah masalah distributed mutual exclusion (mutex). Algoritma Distributed Mutual Exclusion harus berurusan dengan penundaan pesan yang tidak terduga. Secara umum, algoritma mutex memiliki dua tipe yaitu algoritma berbasis tanda (token-based) dan algoritma berbasis izin (permission-based). Algoritma berbasis izin memiliki dua jenis yaitu izin klasik dan sistem himpunan korum (coterie). Maekawa [2] mengemukakan bahwa Distribued Mutual Exclusion adalah contoh klasik dari sebuah algoritma terdistribusi berbasis korum. Kakugawa dkk [3] menguraikan bahwa mekanisme kerja algoritma berbasis himpunan korum lebih efisien daripada mekanisme kerja algoritma berbasis izin klasik.

Molina dan Barbara [4] menguraikan bahwa himpunan korum disebut koteri. Koteri merupakan kumpulan atau himpunan dari beberapa korum yang saling beririsan satu sama lain. Koteri terbagi atas dua jenis yaitu koteri terdominasi dan koteri tak-terdominasi. Dalam uraiannya juga dijelaskan bahwa koteri tak-terdominasi lebih tangguh terhadap kegagalan sistem daripada koteri terdominasi. Lawi dan Rustam [5] mengemukakan bahwa system majority memiliki ketangguhan system terbaik disbanding singleton, grid, dan tree. Selain koteri, kita juga mengenal $k$-koteri yang merupakan pengembangan dari koteri. Jiang dkk [6] memperkenalkan sebuah teorema untuk menguji $k$-koteri tak-terdominasi (nondominated $k$-coteries / ND k-coteries).

Algoritma penggabungan koteri merupakan suatu cara mudah menyusun koteri baru dengan ukuran korum yang lebih besar. Terdapat beberapa cara dalam menggabungkan suatu himpunan korum salah satunya adalah operasi union. Lawi dkk [7]mengemukakan bahwa operasi union didefinisikan dan digunakan jika hanya ada satu himpunan menggabung beberapa node memasuki sistem. Neilsen dkk [8] mengemukakan bahwa penggabungan koteri tak-terdominasi dengan koteri tak-terdominasi akan selalu menghasilkan koteri terdominasi. Namun, Arsal [9] memberikan sebuah contoh penggabungan koteri takterdominasi dengan koteri tak-terdominasi yang menghasilkan koteri tak-terdominasi. Hal ini sekaligus membantah hasil penelitian dari Neilsen dan Mizuno.

Tujuan penelitian ini adalah membangun sebuah definisi penggabungan dua buah $k$-koteri yang menghasilkan $k$-koteri tak-terdominasi dengan menggunakan operasi union diperluas.

\section{METODE}

Jenis penelitian yang digunakan pada penelitian ini ialah berupa kajian literatur atau penelitian pustaka. Pertama-tama penulis mengkaji tentang system himpunan korum (coterie), lalu kemudian mengkaji pengembangan dari koteri yaitu $k$-koteri, $k$-koteri tak-terdominasi, dan sifat-sifat dari $k$-koteri tak-terdominasi. Kemudian membangun sebuah definisi penggabungan dua buah $k$-koteri yang 


\section{Nurhidayah, Armin Lawi, Amir Kamal Amir}

menghasilkan $k$-koteri tak-terdominasi dengan menggunakan operasi union diperluas, dimana dua buah $k$ koteri yang digabungkan memiliki nilai $k$ yang sama dan berjenis sistem $k$-majority.

\section{HASIL PENELITIAN}

\section{Definisi 3.1}

Definisi operasi union diperluas untuk $k$-koteri sebagai berikut:

Misalkan

$$
\begin{aligned}
& C_{1}=\left\{X_{1}, X_{2}, \ldots, X_{i}\right\} \\
& C_{2}=\left\{Y_{1}, Y_{2}, \ldots, Y_{m}\right\}
\end{aligned}
$$

maka,

$$
\begin{aligned}
C_{3}= & C_{1} \otimes C_{2} \\
= & \left\{Q \mid Q \in\left\{\left\{X_{i} \cup Y_{m}\right\},\left\{\left\{\left\{X_{i} \cup X_{j}\right\} \cup\left\{Y_{m} \cap Y_{n}\right\}\right\},\left\{\left\{X_{i} \cup X_{j} \cup X_{k}\right\} \cup\left\{Y_{m} \cap Y_{n}\right\}\right\}\right\},\left\{\left\{\left\{X_{i} \cap X_{j}\right\} \cup\right.\right.\right.\right. \\
& \left.\left.\left.\left.\left\{Y_{m} \cup Y_{n}\right\}\right\},\left\{\left\{X_{i} \cap X_{j}\right\} \cup\left\{Y_{m} \cup Y_{n} \cup Y_{o}\right\}\right\}\right\}\right\},|Q|=\left|X_{i} \cup Y_{m}\right|\right\}
\end{aligned}
$$

dimana $C_{1}$ dan $C_{2}$ adalah $k$-koteri tak-terdominasi.

Untuk membuktikan bahwa koteri hasil penggabungan union diperluas merupakan sebuah $k$ koteri tak-terdominasi dengan cara perhitungan sebagai berikut:

\section{Teorema 3.1}

Misalkan $C_{1}$ dan $C_{2}$ merupakan k-koteri tak-terdominasi atas semesta tak kosong $U_{1}$ dan $U_{2}$, maka $C_{1} \otimes C_{2}$ juga merupakan k-koteri tak-terdominasi jika jumlah korumnya sebagai berikut:

a. Jika $\left|U_{1}\right|,\left|U_{2}\right| \geq\left|Q_{3}\right|$, maka

$$
C_{q}^{n}=\sum_{i=0}^{q} C_{q-i}^{n_{1}} \cdot C_{i}^{n_{2}}
$$

b. Jika $\left|U_{2}\right|,\left|Q_{3}\right| \geq\left|U_{1}\right|$, maka

$$
C_{q}^{n}=\sum_{i=0}^{n_{1}} C_{n_{1}-i}^{n_{1}} \cdot C_{q-n_{1}+i}^{n_{2}}
$$

c. Jika $\left|U_{1}\right|,\left|Q_{3}\right| \geq\left|U_{2}\right|$, maka

$$
C_{q}^{n}=\sum_{i=0}^{n_{2}} C_{q-i}^{n_{1}} \cdot C_{i}^{n_{2}}
$$

dimana

$$
\begin{aligned}
& \left|U_{1}\right|=n_{1} \\
& \left|U_{2}\right|=n_{2}
\end{aligned}
$$




\section{Nurhidayah, Armin Lawi, Amir Kamal Amir}

$$
\begin{aligned}
& \left|U_{3}\right|=n_{1}+n_{2}=n \\
& \left|Q_{3}\right|=q_{1}+q_{2}=q
\end{aligned}
$$

\section{PEMBAHASAN}

Penelitian ini menunjukkan bahwa penggabungan $k$-koteri tak-terdominasi dengan $k$-koteri takterdominasi menghasilkan $k$-koteri tak-terdominasi. Ukuran himpunan semesta $U_{1}$ dan $U_{2}$ tidak mempengaruhi ukuran korum hasil penggabungan. Definisi operasi union diperluas yang diperoleh hanya berlaku untuk dua buah $k$-koteri tak-terdominasi $C_{1}$ dan $C_{2}$ yang memiliki nilai $k$ yang sama. Berikut contohnya:

\section{Contoh 4.1}

$C_{1}$ merupakan 3-koteri tak-terdominasi atas $U_{1}=\{1,2,3,4,5,7,8\}$ dan $C_{2}$ merupakan 3-koteri takterdominasi atas $U_{2}=\{a, b, c, d, e\}$.

maka

$$
\begin{aligned}
& W_{1}=\left|Q_{U_{1}}\right|=\left\lceil\frac{n+1}{k+1}\right\rceil=\left\lceil\frac{8+1}{3+1}\right\rceil=\left\lceil\frac{9}{4}\right\rceil=3 \\
& C_{1}=\{\{1,2,3\},\{1,2,4\},\{1,2,5\},\{1,2,6\}, \cdots,\{5,7,8\},\{6,7,8\}\} \\
& W_{2}=\left|Q_{U_{1}}\right|=\left\lceil\frac{n+1}{k+1}\right\rceil=\left\lceil\frac{5+1}{3+1}\right\rceil=\left\lceil\frac{6}{4}\right\rceil=2 \\
& C_{2}=\{\{a, b\},\{a, c\},\{a, d\},\{a, e\},\{b, c\},\{b, d\},\{b, e\},\{c, d\},\{c, e\},\{d, e\}\}
\end{aligned}
$$

Untuk memperoleh $k$-koteri tak-terdominasi dari gabungan kedua $k$-koteri tak-terdominasi $C_{1}$ dan $C_{2}$ digunakan definisi yang telah kita peroleh sebelumnya yaitu

$$
\begin{aligned}
C_{3}= & C_{1} \otimes C_{2} \\
= & \left\{Q \mid Q \in\left\{\left\{X_{i} \cup Y_{m}\right\},\left\{\left\{\left\{X_{i} \cup X_{j}\right\} \cup\left\{Y_{m} \cap Y_{n}\right\}\right\},\left\{\left\{X_{i} \cup X_{j} \cup X_{k}\right\} \cup\left\{Y_{m} \cap Y_{n}\right\}\right\}\right\},\left\{\left\{\left\{X_{i} \cap X_{j}\right\} \cup\right.\right.\right.\right. \\
& \left.\left.\left.\left.\left\{Y_{m} \cup Y_{n}\right\}\right\},\left\{\left\{X_{i} \cap X_{j}\right\} \cup\left\{Y_{m} \cup Y_{n} \cup Y_{o}\right\}\right\}\right\}\right\},|Q|=\left|X_{i} \cup Y_{m}\right|\right\}
\end{aligned}
$$

dimana

$X_{i} \cup Y_{m}$

$=\{\{1,2,3, a, b\},\{1,2,3, a, c\}, \cdots\{6,7,8, d, e\}\}$

$\left\{\left\{X_{i} \cup X_{j}\right\} \cup\left\{Y_{m} \cap Y_{n}\right\}\right\},\left\{\left\{X_{i} \cup X_{j} \cup X_{k}\right\} \cup\left\{Y_{m} \cap Y_{n}\right\}\right\}$

$=\{1,2,3,4,5\},\{1,2,3,4,6\}, \cdots,\{4,5,6,7,8\},\{1,2,3,4, a\}, \cdots,\{5,6,7,8, e\}$, 


\section{Nurhidayah, Armin Lawi, Amir Kamal Amir}

$$
\begin{aligned}
& \left\{\left\{X_{i} \cap X_{j}\right\} \cup\left\{Y_{m} \cup Y_{n}\right\}\right\},\left\{\left\{X_{i} \cap X_{j}\right\} \cup\left\{Y_{m} \cup Y_{n} \cup Y_{o}\right\}\right\} \\
& =\{a, b, c, d, e\},\{1, a, b, c, d\}, \cdots,\{8, b, c, d, e\},\{1,2, a, b, c\}, \cdots,\{7,8, c, d, e\}
\end{aligned}
$$

Suatu himpunan tak kosong $\mathbf{C}$ dikatakan $k$-koteri jika memenuhi definisi berikut:

Definisi 4.1. (K-koteri) Sebuah koleksi himpunan tak kosong $\boldsymbol{C}$ adalah k-koteri atas semesta $U$ jika dan hanya jika C memenuhi (Lawi dkk $\left.{ }_{\bar{亠}} 2005\right)$

1. Saling lepas: untuk setiap $h$ korum yang saling lepas dalam $H=\left\{Q_{1}, \ldots, Q_{h}\right\} \subseteq C$ dengan $h<$ $k$, maka $\exists Q \in C$ sedemikian sehingga $Q \cap Q_{i}=\emptyset, \forall Q_{i} \in H$.

2. Irisan: untuk sembarang l korum $L=\left\{Q_{1}, \ldots, Q_{l}\right\} \subseteq C$ dengan $l>k$, maka terdapat pasangan $Q_{i}, Q_{j} \in L$ sedemikian sehingga $Q_{i} \cap Q_{j} \neq \emptyset, i \neq j$.

3. Minimalitas: $Q_{i} \nsubseteq Q_{j}, \forall Q_{i}, Q_{j} \in C, i \neq j$.

Untuk ukuran korum $k$-koteri didefinisikan sebagai berikut:

Definisi 4.2.( $k$-Majority coterie) Misalkan $W=\left\lceil\frac{n+1}{k+1}\right\rceil$, dimana $n(>k)$ adalah jumlah node dalam sistem. Himpunan k-majority coterie dari himpunan tak-kosong $U$ adalah $\operatorname{Maj}_{k}=\left\{Q_{i}(\subseteq U),\left|Q_{i}\right|=W\right\}$.

Sebuah $k$-koteri dikatakan terdominasi atau tak-terdominasi jika memenuhi definisi berikut:

Definisi 4.3.(Sistem korum terdominasi dan tak - terdominasi). Misalkan $\boldsymbol{C}$ dan $\boldsymbol{D}$ adalah koteri dalam semesta $U$. C mendominasi $\boldsymbol{D}$ (ditulis $\boldsymbol{C}>\boldsymbol{D}$ ) jika dan hanya jika

1. $C \neq D$

2. $\forall Q \in \boldsymbol{D}, \exists Q^{\prime} \in \boldsymbol{C}$ sedemikian sehingga $Q \subseteq Q^{\prime}$.

Jika tidak terdapat koteri lain yang mendominasi maka $\boldsymbol{D}$ dikatakan tak-terdominasi atau non-dominated (ND korum system). (Peleg dkk, 1995)

Suatu koteri dikatakan tak-terdominasi apabila tidak ditemukan korum lain yang mendominasi koteri tersebut. Pada penelitian ini diperoleh juga sebuah teorema untuk membuktikan bahwa $k$-koteri hasil penggabungan union diperluas merupakan sebuah $k$-koteri tak-terdominasi. Berikut contohnya

\section{Contoh 4.2.}

Diketahui $C_{1}$ dan $C_{2}$ merupakan 2-koteri tak-terdominasi atas $U_{1}=\{1,2,3,4,5\}$ dan $U_{2}=\{a, b, c, d, e\}$ dengan ukuran korum hasil penggabungannya adalah sebagai berikut:

$$
\begin{aligned}
\left|Q_{1}\right|+\left|Q_{2}\right| & =\left\lceil\frac{n_{1}+1}{k+1}\right\rceil+\left\lceil\frac{n_{2}+1}{k+1}\right\rceil \\
& =\left\lceil\frac{5+1}{2+1}\right\rceil+\left\lceil\frac{5+1}{2+1}\right\rceil
\end{aligned}
$$




\section{Nurhidayah, Armin Lawi, Amir Kamal Amir}

$$
\begin{aligned}
& =\left\lceil\frac{6}{3}\right\rceil+\left\lceil\frac{6}{3}\right\rceil \\
& =4
\end{aligned}
$$

Dengan jumlah korum sebagai berikut:

Karena

$\left|U_{1}\right|,\left|U_{2}\right| \geq\left|Q_{3}\right|$

maka

$$
\begin{aligned}
C_{q}^{n} & =\sum_{i=0}^{q} C_{q-i}^{n_{1}} \cdot C_{i}^{n_{2}} \\
& =\sum_{i=0}^{4} C_{4-i}^{5} \cdot C_{i}^{5} \\
& =C_{4}^{5} \cdot C_{0}^{5}+C_{3}^{5} \cdot C_{1}^{5}+C_{2}^{5} \cdot C_{2}^{5}+C_{1}^{5} \cdot C_{3}^{5}+C_{0}^{5} \cdot C_{4}^{5} \\
& =210
\end{aligned}
$$

\section{KESIMPULAN DAN SARAN}

Berdasarkan hasil penelitian, maka dapat disimpulkan bahwa pada penelitian ini diperoleh sebuah definisi penggabungan $k$-koteri tak-terdominasi dengan $k$-koteri tak-terdominasi yang menghasilkan $k$-koteri tak-terdominasi, serta diperoleh pula sebuah teorema yang membuktikan bahwa $k$ koteri yang diperoleh adalah $k$-koteri tak-terdominasi. Berdasarkan kesimpulan maka penulis merekomendasikan untuk mengembangkan definisi operasi penggabungan beberapa k-koteri-tak terdominasi $C_{1} \otimes C_{2} \otimes C_{3} \otimes \cdots$.

\section{DAFTAR PUSTAKA}

[1] Lawi, A., dkk. 2006. A Quorum based distributed conflict resolution algorithm for bounded capacity resources. Lecture Notes in Computer Science (LNCS), Vol. 4331, Springer Verlag-Berlin, Hal. $135-144$.

[2] Maekawa. 1985. A $\sqrt{n}$ algorithm for mutual exclusion in decentralized systems. ACM Trans. Comput. Systems 3(2), Hal. 145-159.

[3] Kakugawa, dkk. 1993. Availability of k-Coterie.IEEE Transactions on Computer.Vol. 42, No. 5.

[4] Molina dan Barbara. 1985. How to assign votes in a distributed system.J . ACM 32(4), Hal.841-860.

[5] Lawi, A dan Rustam 2008. Availability Comparison of Quorum Systems in Distributed Systems. Proceedings of The $1^{\text {st }}$ Makassar International Conference on Electrical Engineering and Informatics, Hasanuddin University, Makassar, Indonesia. ISBN : 978-979-18765-0-6. 


\section{Nurhidayah, Armin Lawi, Amir Kamal Amir}

[6] Jiang, Jhen-Ruey dan Shing-Tsaan Huang. 1994. Obtaining Nondominated K-Coteries for FaultTolerant Distributed K-Mutual Exclusion. Department of Computer Science National Tsing Hua University HsinChu, Taiwan, 30043 R. 0.C.

[7] Lawi, A., dkk. 2005. A Simple Quorum Reconfiguration for Open Distributed Environments. International Conference on Parallel and Distributed System, IEEE Computer Society.

[8] Neilsen, Mitchell L. dan Masaaki Mizuno. 1992. Coterie Join Algorithm. IEEE Transactions on Parallel and Distributed System, Vol. 3, No. 5, Hal.759-765.

[9] Arsal, Armayani. 2016. Operasi Penggabungan Himpunan Korum yang Menghasilkan Koteri Takterdominasi Pada Sistem Terdistribusi.Hasanuddin University, Makassar, Indonesia. 